$\left.\frac{94 / 1 / 28}{10 / 5}\right|_{\text {LA-7450-MS }}$ Informal Report Whing

Techniques for Measurement of Densities of PBX Samples at Other than Room Temperature

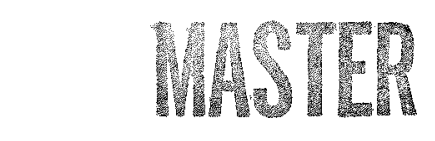

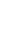
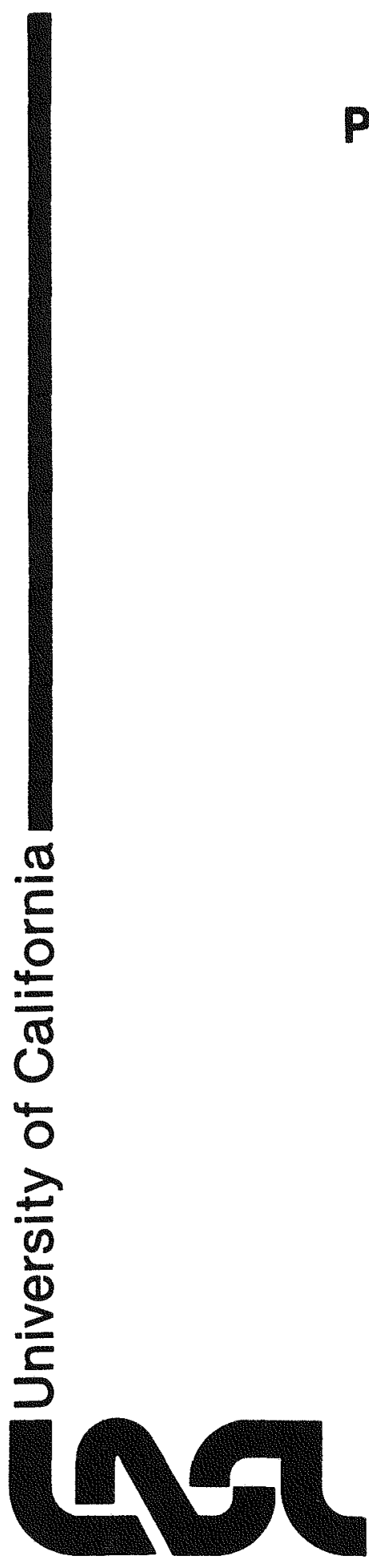
This report was prepared as an account of work sponsored by the United States Government. Neither the United States nor the United States Department of Energv, nor any of their employees, nor any of their contractors, subcontractors, or theix emploves. makes any warranty, express or tmplied. or completeness, ar usefulness of any information apparacys, product or process disclosed or represents that its use would not infringe privately owned rights. 


\section{DISCLAIMER}

This report was prepared as an account of work sponsored by an agency of the United States Government. Neither the United States Government nor any agency Thereof, nor any of their employees, makes any warranty, express or implied, or assumes any legal liability or responsibility for the accuracy, completeness, or usefulness of any information, apparatus, product, or process disclosed, or represents that its use would not infringe privately owned rights. Reference herein to any specific commercial product, process, or service by trade name, trademark, manufacturer, or otherwise does not necessarily constitute or imply its endorsement, recommendation, or favoring by the United States Government or any agency thereof. The views and opinions of authors expressed herein do not necessarily state or reflect those of the United States Government or any agency thereof. 


\section{DISCLAIMER}

Portions of this document may be illegible in electronic image products. Images are produced from the best available original document. 
LA-7450-MS

Informal Report

UC-45

Issued: August 1978

\title{
Techniques for Measurement of Densities of PBX Samples at Other than Room Temperature
}

\author{
John F. Baytos \\ Carlos A. Martinez
}
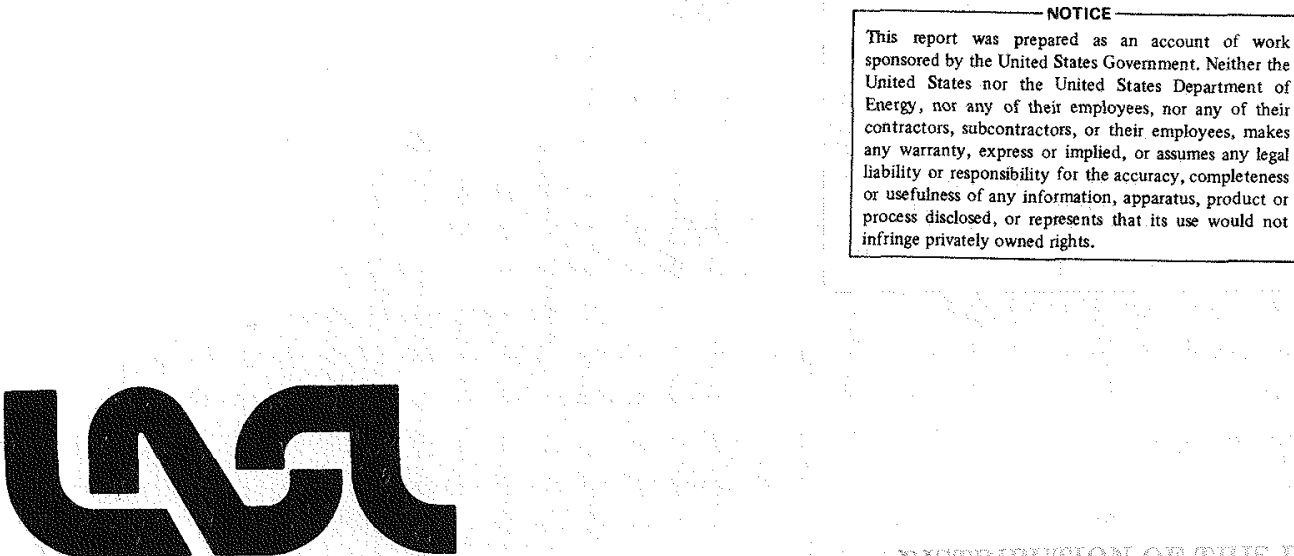


\title{
TECHNIQUES FOR MEASUREMENT OF DENSITIES OF PBX SAMPLES
}

\author{
AT OTHER THAN ROOM TEMPERATURE
}

by

John F. Baytos and Carlos A. Martinez

\section{ABSTRACT}

Techniques for measuring the density of PBX samples from $-54^{\circ} \mathrm{C}$ to $+70^{\circ} \mathrm{C}$ are described. The method is based on the displacement of a liquid by a sample, but with two additional controlling steps. The specific gravity of the immersion fluid is determined by weighing an immersed quartz rod at the temperature of interest, and the temperature is monitored by a thermocouple-driven digital thermometer.

\section{INTRODUCTION}

The measurement of densities at room temperature of sample cylinders of explosive castings or pressings is a routine operation. The technique uses the classic Archimedes's principle, the displacement of a liquid by the sample. Consequently, when our laboratory needed a method for measuring the density of pressed samples of PBX 9502 (a plastic bonded explosive) at temperatures other than room temperature, namely, $-54^{\circ} \mathrm{C}$ and $+70^{\circ} \mathrm{C}$, we considered several approaches, including the pycnometer method, ${ }^{-3}$ and decided to adapt the usual immersion techniques for use at low and high temperatures.

\section{DISCUSSION}

To operate at low temperatures, it was necessary to find an immersion fluid that wets the samples and has a low viscosity at $-54^{\circ} \mathrm{C}$. Ethanol was chosen, but our calculations showed that we needed to know the specific gravity of the ethanol more accuretely than handbook values. Furthermore, pure ethanol is hygroscopic and changes specific gravity as water is absorbed from condensate on the cold sample. Therefore, we used 190-proof (95\%) ethanol.

The specific gravity of the ethanol at the temperature of interest $\left(-54^{\circ} \mathrm{C}\right)$ was measured through the use of fused quartz cylinders. Because the linear coefficient of thermal expansion of fused quartz is $0.54 \times 10^{-6} \mathrm{~m} / \mathrm{m}^{\circ} \mathrm{C}$, the change in volume from room temperature to $-54^{\circ} \mathrm{C}$ is less than $0.0002 \%$, which is less than our experimental error in routine room-temperature density determinations. The quartz cylinder was immersed in the cold ethanol to bring it to the test temperature, and its immersed weight was determined after every sample density determination. From the mass, the immersed weight, and known density of the quartz, we calculated the specific gravity of the ethanol at the temperature of interest.

The procedure for the $+70^{\circ} \mathrm{C}$ density measurement was the same, except for the use of thermostated water as the immersion 1iquid. The specific gravity of the water determined at the high temperature by using 
a quartz rod agreed with the handbook value for that temperature.

The temperature of the immersion Iiquid was measured with a thermocouple and digital microvoltmeter, to detect any changes with more sensitivity than can be read with a thermometer. When the sample was transferred from its thermal conditioning atmosphere to the immersion fluid, there usually was a slight mismatch of temperatures. The thermocouple readout allowed us to track weight changes and temperature changes as the system equilibrated. We could easily determine the precision of the density measurements from several weighings at slightly different temperatures. We maintained the temperature within one degree during a weighing.

\section{III, EXPERIMENTAL}

Because the procedure follows the basic room-temperature method, only the added steps and precautions necessary to make it feasible at the low temperature and then at the high temperature are described here.

The samples were cylinders (10-mm-diam by 20-mm-high), but could have been any reasonable shape or size that can be accommodated in the immersion vessel in the analytical balance. The mass of each sample was determined at room temperature at the start.

The cold-temperature samples were thermally conditioned for a minimum of two hours in a cold bath maintained at the test temperature. To minimize condensation on the sample surface, each sample was fastened to a fine hang-wire, then sealed with a rubber stopper into a dry test tube. The enclosed sample was then immersed in the cold bath and kept there until needed.

The immersion fluid, ethanol, was contained in a 250-m1 wide-mouth thermos jar. A fine wire, copper/Constantan thermocouple was inserted into the ethanol out of the way of the sample, and connected to a digital microvoltmeter. The quartz cylin- der (10-mm-diam by $20-m m-h i g h)$ attached to its hang-wire was suspended in the ethanol, out of the way of the sample, on a wire loop hung over the side of the thermos. Dry ice was added in small crushed pieces to cool the ethanol to the test temperature. When the temperature reached $-54^{\circ} \mathrm{C}$, the ethanol was stirred and allowed to equilibrate until the bubbling from the dry ice stopped. The thermos was then placed in the weighing chamber of a single-pan analy ical balance on a bridge straddling the weighing pan.

Each conditioned sample was removed from its sealed test tube and quickly transferred to the ethanol. If this step is not done quickly, condensate may appear on the sample. The sample hang-wire was attached to the suspension hook of the balance. The immersed weight was determined and recorded along with the temperature of ethanol. The temperature and immersed weight usual $1 \mathrm{y}$ remained stable for at least a minute. After the sample was removed, its hang-wire was taken off and weighed in the ethanol, and its weight was subtracted from the combined immersed weight. The wire holding the quartz cylinder was then attached with the ald of tweezers to the suspension hook, and the cylinder was weighed in the ethanol. The wire was then detached from the suspension hook and the quartz was lowered into the ethanol to await its next weighing. The quartz hang-wire was weighed but once, at the completion of a series of immersion weighings, and the immersed weight of the quartz cylinder was corrected.

Each sample for the high-temperature immersed weighing was attached to a fine hang-wire and thermally conditioned in a circulating air oven at the temperature of interest for a minimum of two hours.

A 250-ml jacketed beaker was used to hold the immersion fluid, water, for the elevated-temperature weighings. The temperature was kept constant by circulating water from a temperature-controlled system. The thermocouple and quartz rod were placed in 
the immersion fluid as for the cold test. The jacketed beaker and its attachments were placed in the weighing chamber just before weighing to prevent moisture condensation on the upper balance parts.

The sample was transferred from the oven to the water, and the upper loop of the hang-wire was attached to the suspension hook of the balance. The immersed weight of the sample and the temperature of the water were recorded. The temperature and immersed weight did not change significantly within the time it took to make a weighing. After the sample was removed, its hang-wire was weighed and subtracted from the combined immersed weight. The quartz rod was then weighed in the same manner as in the cold weighings.

As the mass and immersion weight of the sample, the mass and immersion weight of the quartz, and the temperature of the immersion fluid were known, it was possible to calculate the density of the sample at the temperature of interest.

The specific gravity of the fluid is calculated as follows:

Sp gr at $T_{i}=\frac{2.208(W d q-W w q)}{(W d q)}$

where $\mathrm{Sp} g r=$ specific gravity at the test temperature, $T_{i}$, in $\mathrm{g} / \mathrm{cm}^{3}$,

$\mathrm{T}_{i}=$ test temperature, ${ }^{\circ} \mathrm{C}$,

Wdq $=$ mass of quartz in $\mathrm{g}$,

Wwq = immersed weight of quartz corrected for hang-wire weight at the test temperature in $\mathrm{g}$, and

$2.208=$ density of quartz in $\mathrm{g} / \mathrm{cm}^{3}$.

The density of the test sample is calculated as follows:

Density at $T_{i}=\frac{(W d s)(S p g r)}{(W d s-W w s)}$,

where Density = mass/volume at the test temperature, $\mathrm{T}_{i}$ in $\mathrm{g} / \mathrm{cm}^{3}$,

$\begin{aligned} \text { Wds }= & \text { mass of the sample in } \mathrm{g}, \\ \text { Wws }= & \text { immersed weight of sample } \\ & \text { corrected for hang-wire } \\ & \text { weight at the test temper- } \\ & \text { ature in } \mathrm{g}, \text { and } \\ \text { Sp gr }= & \text { value from Eq. (1). }\end{aligned}$

IV. RESULTS

The densities of PBX 9502 samples from different lots determined at various temperatures are shown in Table $I$.

Densities at room temperature are shown for purposes of comparison. The spread on one sample repeated ten times is 0.003 , and the standard deviation is 0.0009 . Duplicate results on the $\mathrm{PBX}$ samples run at $-54^{\circ} \mathrm{C}$ and at $+70^{\circ} \mathrm{C}$ showed precision equivalent to that obtained at room temperature. Density measurements by this method proceed very rapidly, as exrors caused by condensation and temperature variation have been minimized. With proper precautions, densities can be determined readily at any temperature within the range of $-54^{\circ} \mathrm{C}$ to $+70^{\circ} \mathrm{C}$.

TABLE I

DENSITY OF PBX 9502

\begin{tabular}{cccc} 
Sample & \multicolumn{3}{c}{ Density } \\
\cline { 3 - 4 } \begin{tabular}{c} 
Number \\
\cline { 3 - 4 }
\end{tabular} & $\begin{array}{l}\text { At }-54^{\circ} \mathrm{C} \\
\left(\mathrm{g} / \mathrm{cm}^{3}\right)\end{array}$ & $\begin{array}{c}\text { At }+21^{\circ} \mathrm{C} \\
\left(\mathrm{g} / \mathrm{cm}^{3}\right)\end{array}$ & $\begin{array}{c}\text { At }+70^{\circ} \mathrm{C} \\
\left(\mathrm{g} / \mathrm{cm}^{3}\right)\end{array}$ \\
2 & 1.892 & 1.874 & 1.858 \\
3 & 1.901 & 1.883 & 1.868 \\
4 & 1.897 & 1.875 & 1.860 \\
5 & 1.902 & 1.883 & 1.867 \\
1.907 & 1.891 & 1.871
\end{tabular}

\section{ACKNOWLEDGMENTS}

This work was an outgrowth of discussions with J. L. Parkinson, H. L. Flaugh, and M. Schwartz, who wanted to verify linear thermal coefficients of expansion of PBX 9502 at high and low temperatures, provided that an easy technique could be developed to make density measurements. 


\section{REFERENCES}

1. American Society for Testing and Materials, "Specific Gravity and Density of Plastics by Displacement, Test for " (D792-66) 35, ASTM, Philadelphia, (1975).
2. L. W. Black, "Density Measurement of Solid Objects, "Instruments and Control Systems 43 , No. 12 (1970), p, 25.

3.J.J. Bensch and H. J. Brynard, "New Approach to Density Measurements using Archimedes's Principle," Nature Phys. Sci. $239(1972)$, p. 96. 